\title{
Margem de Papel ou Corpo Despedaçado do Texto ${ }^{1}$
}

\author{
PAULO SÉRGIO NOLASCO DOS SANTOS ${ }^{2}$
}

$\mathrm{O}$ artigo propõe-se a refletir a travessia dos signos do universo socioeconômico do Estado do Mato Grosso do Sul e a constituição da identidade e representação em textos diversos da literatura e da crítica cultural que tematizam a questão. Adotando uma perspectiva baseada na crítica cultural e/ou nos estudos culturais, o artigo analisa a complexidade da relação entre narração e representação, elaborando uma síntese da noção de região num espaço que compreende o entorno do pantanal sul-mato-grossense. As conclusões do trabalho indicam que a travessia e circulação dos signos culturais se dão enquanto agenciamento discursivo, que ora reflete o objeto da representação, ora o mascara, pois a natureza desse objeto se demonstra enquanto tecido emblemático de um corpo despedaçado.

Palavras-chave: Identidade e representação; estudos culturais; crítica. 
O longo processo político-cultural de divisão do Estado de Mato Grosso não só acabou se inscrevendo como grande página da história regional, mas acaba interessando principalmente pelos silêncios, pelas lacunas e por aquilo que faz calar. A Revista MS Cultura dedicou parte especial do seu número 3 ao tema da divisão, avaliando "um século de história", ou, como se intitula sintomaticamente um dos ensaios aí publicado: "História e estórias de uma velha pendenga revisitada". Da leitura desses ensaios, chamou-me a atenção a indisposição, ou denegação, em falar sobre o assunto da divisão, especialmente quando um dos ensaístas é conhecido pesquisador e professor da universidade, cuja opinião é ouvida com reverência ${ }^{3}$.

Tendo reunido farto material de referência dedicado ao complexo cultural no meu estado, interessando-me sobretudo pela discussão acerca da construção identitária do MS, e na qualidade de examinador de dissertação de mestrado que se ocupou do assunto, verifiquei o quanto são contraditórias, senão confusas, as opiniões sobre a questão da representação cultural, especialmente no que diz respeito aos aspectos que me proponho a discorrer neste trabalho.

Tive a oportunidade de escrever sobre o assunto, que resultou em capítulo publicado no livro Culturas, contextos e discursos, organizado pela professora Tania Franco Carvalhal ${ }^{4}$. Chamei a atenção, então, para a complexidade de que se reveste o tecido cultural de um dos mais novos estados da federação - o Mato Grosso do Sul - principalmente quando enfocadas as relações interculturais de entre os dois estados - Mato Grosso e Mato Grosso do Sul - e ainda pelos mesmos cruzamentos interculturais que se mantêm com países vizinhos, notadamente o Paraguai e a Bolívia.

Dito isto, meu objetivo é reler alguns dos textos que tematizam a questão da identidade e representação cultural do MS, procurando constatar que a dinâmica rotatória dos nomes - MT, MS, PT - corresponderia, reflexiva e sintomaticamente, não só à insolvência dos "Nomes" mas também ao caráter dinâmico, vivo e por assim dizer cambiante do tecido cultural, da própria construção da representação identitária.

A sigla PT tem sido apontada como a que abreviaria o ato de rebatizar o estado com o nome de Pantanal, o que foi objeto de deliberação em sessão plenária da $\mathrm{OAB} / \mathrm{MS}$, em 30/04/99, incumbida de analisar e deliberar sobre 
a proposta de mudança do nome do estado de Mato Grosso do Sul para o de Estado do Pantanal. Daí para cá inúmeros folders e/ou cartazes se incumbiram de vender e/ou fabricar a idéia "Estado do Pantanal"s.

Não é meu objetivo revisitar um século de atos e empreendimentos políticos ou feitos históricos que fizeram avolumar copiosas páginas acerca da divisão do estado e que hoje compõem farto material da historiografia regional. Apenas para ilustrar a questão, menciono o relato do parecerista da $\mathrm{OAB}$ que refere o nascimento do Estado de Maracaju, criado em 11/07/ 32, que duraria apenas 82 dias. Prossegue o parecerista citando importante reflexão da professora Idara Duncan, sobre a qual queremos juntar nosso questionamento na tentativa de ampliar e redimensionar, a seguir, a constatação por ela formulada: "com referência a nossa identidade cultural, a separação criou-nos um inusitado impasse quando impeliu-nos frente ao espelho a indagar: - E agora, quem somos?" (Duncan apud Couto, 1999).

A citação, assim formulada e aqui recolocada no contexto desta análise, evoca uma outra citação, que, no macrotexto da divisão, toma a forma de citação em exergo, uma vez que está inscrita na lápide da sepultura do grande herói/mártir da emancipação do sul do Mato Grosso: o Coronel João Ferreira Mascarenhas, ou, simplesmente caudilho Jango Mascarenhas. A lápide em sua sepultura, no cemitério de Aquidauana, traz o seguinte epitáfio inscrito em francês: "Passant ne pleure pas ma mort, can je suis vif même quand je suis mort" (Ao passares por aqui, não chores, porque mesmo morto, continuo vivo) (Duncan apud Couto, 1999).

Assim escrito, o epitáfio torna-se o testemunho lapidar que sintetiza o mal-estar do morto/fantasma que, ainda que morto, continua a viver. Da época da inscrição/morte, 21/10/1901, até os dias de hoje, cruzando com a citação de Idara Duncan, o sintoma pode ser assim transcrito na grande crônica contemporânea que especula acerca do melhor gentílico para batizar o corpo morto/vivo que constituiria a identidade e representação cultural dessa unidade da federação. Portanto, se morto continua a viver, ou, ainda que morto continua a viver, tal condição passa a constituir o lugar fantasmático do espelho que nos obriga à pergunta, ao mesmo tempo em que nos coloca no lugar de impasse, indecisão, frente à(s) alternativa(s) da escolha de um gentílico.

Ora, o ato de escolha, por si só, não seria problemático e nem objeto de "pendengas". Só o é, na medida em que a própria história da criação do novo estado se dá com sobressaltos e de açodado, acabando por deslanchar vários atos pomposos e medidas rompantes à maneira de uma cruzada, 
espécie de jornada ou maratona física que assim justificariam ou refletiriam a hegemonia do tecido cultural. Como se verá, em se tratando de um "tecido", é também um "complexo" - portanto, "complexo cultural", cuja representação resistiria àquelas demandas que parecem resultar muito mais na eficácia de um ato político do que numa busca da construção realmente identitária do novo estado de MS.

Engrossando o lugar comum desta crônica da construção identitária, constata-se o equívoco de articulistas e homens de letras que lêem de maneira equívoca e/ou redutora os materiais, a vida cultural e os produtos da cultura, na tentativa de aí indexar, numa espécie de teia e nó, a esgarçada complexidade do tecido cultural, que se mostra dinâmico, resistente e volátil como toda matriz representativa, rotativa como a própria ciranda dos "Nomes", que originariamente foi MT, tornou-se Maracaju, passou a ser MS e quer se tornar PT (Pantanal) ou Guaicuru.

Diante disto, pretendo discorrer sobre o que na minha observação reflete uma vontade de construir e fabricar um gentílico que, por força dessa vontade de representação, legitimasse um "Nome" ao qual pudesse refletir a própria inaptidão para ler, não mais o tecido cultural somente e por si só, de um lado, mas de ler a própria representação - os signos, ícones e símbolos - da cultura também como tecido de especial e particular complexidade, de outro.

Bastaria tão-somente citar alguns exemplos retirados do trabalho de José Calos Zilliani, intitulado Tentativas de construções identitárias em Mato Grosso do Sul (1977-2000). Nesse trabalho (tive a honra de participar do exame da dissertação de mestrado em História do Brasil) encontra-se reunido vasto quadro de textos-fontes que o autor utilizou como objeto de sua pesquisa. Marca, deixando entrever ao final da leitura, o quanto a questão da escolha de um nome para o estado iria se tornar uma bandeira calcada num referente que, supostamente melhor ou idealmente, representasse senão o constituinte identitário mas que seria representado por quaisquer referentes, aleatórios, ou único dentro do recorte operado na tentativa de fazer emantar sobre uma região específica - recorte físico, geofísico no mapa sentidos de identidade facilmente questionáveis.

Assim restaria evidente que uma questão naturalmente afeta à particularidade e complexidade do processo de semiotização do referente ou, grosso modo, ao signo propriamente dito, passe a ser mal interpretada ou forçosamente interpretada, pois que integrante do emaranhamento do sujeito, dos sujeitos políticos, que querem, por meio do ato político posto em opera- 
ção, tornar natural ou fazer parecer natural a representação de um dos elementos que, dentre outros, compõem a semiotização da cultura como um todo. Os depoimentos dos vários narradores, relatando suas histórias de vida, colhidos pela professora Glorinha, bem refletem o "impasse frente ao espelho", como relata o historiador, jornalista e pioneiro campo-grandense Edson Carlos Contar: "Tenho uma crônica: A Babel que deu certo, cujo título se adequa perfeitamente ao caldo cultural que é Campo Grande" (Sá Rosa, 1999, p. 36).

Vejamos alguns dos textos-fontes que compõem a crônica despedaçada, corpo-fantasma que revive o impasse do sujeito frente ao espelho.

$$
* * *
$$

Duas crônicas publicadas no jornal O Progresso, de 10/05/99, refletem todo um sintoma: ambas se utilizam da "seriema" - conhecida ave da região e motivo da famosa canção folclórica intitulada "A seriema de Mato Grosso" - para se auto-intitularem "Pra quem fica a seriema" e "Estado do PT e a seriema". A publicação das duas crônicas dá-se em reportação à mesma matéria publicada por ocasião da criação do Estado de Mato Grosso do Sul (11/10/77), com o autor de uma das crônicas informando da sua ampla repercussão e da pergunta "pra quem fica a seriema?" por todo o estado, à época da divisão $0^{6}$.

Curioso não é só a indecisão sobre o insolúvel destino da "seriema", mas também a patética pergunta sobre se a referida canção passaria a denominarse "Seriema do Pantanal", considerando-se agora que o Governo Zeca do PT (governo popular), em franca campanha pela mudança, encaminhou à OAB matéria para apreciação, bem como fez divulgar diversos cartazes/folders com fotografias pantaneiras levando a inscrição "Estado do Pantanal".

Segundo o articulador da referida crônica, caso o estado passasse a chamar-se Pantanal, instalar-se-ia uma polêmica quanto à escolha da sigla que melhor indicaria seu nome: estado do PA, do PR, do PN, do PAN, ou do PT? Nenhuma dessas siglas; só poderia ser, então, Estado do PT. Este então instalava um fator de indecisão: "Será que ninguém pensou nisso antes? Estado do PT, governador Zeca do PT." Para além do chiste, do senso humorístico que percebemos na crônica acima, ela mesma oferece ramificações para outros textos de cunho acentuadamente maniqueístas, de vieses estereotipados que tentaram assim, politicamente, construir os ícones da identidade sul-mato-grossense.

Em 1979 cria-se o movimento cultural denominado Unidade Guaicuru, 
cujo objetivo, que já vinha sendo construído com base na história dos índios guaicuru - os índios cavaleiros de Mato Grosso -, era o de promover o gentílico "guaicuru" em substituição ao já criado estado de MS. Como carrochefe, à frente do movimento ia o artista plástico Henrique Spengler, que, aproveitando os ícones e cores da arte kadwéu como elementos constituintes do seu trabalho, se autodenominou um guaicuru legítimo - como se num ato de troca de vestuário, o artista, representando os cidadãos da região, pudesse elaborar o trans/vestimento, a trans/versão da representação, então legitimada pelo simples desfilar dos pressupostos ícones de identidade sul-mato-grossense. Não se observou aí que a própria nação guaicuru se representava por várias tribos e diferentes práticas culturais, conseqüentemente, praticando "entre si profundas divergências culturais" (Figueiredo apud Ziliani, 2000, p. 62).

Nos meses que se seguiram à instalação do governo do estado recémcriado, o conjunto musical Grupo Acaba, incorporando elementos pantaneiros (índio, fazendeiro, vaqueiro, fauna, flora), numa iconografia encomiástica desses valores, chegou a andar "em caravanas com o governador e seus secretários e assessores", o que, segundo Ziliani, constituiu uma "verdadeira cruzada fundadora de um novo tempo" (Ziliani, 2000, p. 76).

O que se desprende dessas atitudes, no conjunto das ações "orientadas" com vistas a pôr em agenciamento uma linguagem, um discurso sobre a representação, é a inadequação dessas ações mediante o imenso "painel de registro das contradições de Mato Grosso do Sul", como observou a professora Maria da Glória Sá Rosa, com sua fina percepção da cultura (Sá Rosa apud Ziliani, 2000, p. 77). Observa-se assim algo como uma tradição inventada, que não dá conta de refletir criticamente a variegada tessitura da cultura, senão a partir de signos estereotipados.

Não estariam, freqüentemente, os promotores da identidade, e por isso comprometidos com o seu trabalho em curso, colocando-se a serviço da vontade de políticos que rivalizam na escolha do melhor gentílico para o estado? Neste caso, não estariam sendo cooptados pelo poder político? Em nome da busca das raízes e da identidade cultural ampliou-se o leque da animosidade e da contradição.

Em apresentação no Teatro Aracy Balabanian, o mesmo Grupo Acaba protestou contra a Fundação de Cultura, pelo que chamou de "conivência com as ações do governo de Mato Grosso do Sul", que, aparentemente, promovia a country music em total descaso com a música regional (Lacerda apud Ziliani, 2000, p. 77). Ainda em nome do compromisso com o regional 
e com a realidade, sem se considerar a complexidade, o emaranhamento que envolve o aspecto simbólico dessas referências, articulistas, em colunas do jornal Correio do Estado, alternavam-se, ora na condenação da música oriunda dos grandes centros - nacional ou internacional - na tentativa de fugir "a essa influência, e também à nefasta ação do colonialismo cultural externo", ora na defesa de uma ação que visasse, apaixonada e urgentemente, a "resgatar a nossa memória e fortalecer os nossos traços culturais básicos, espelhando as formas de manifestações culturais do sertão, do serrado, que são múltiplas e não codificadas" (sic). (Correio do Estado apud Ziliani, 2000, p. 67).

De forma maniqueísta, não percebeu o analista, na sua condenação ao que não fosse genuinamente regional, o fato de músicos como Tetê Espíndola e Paulo Simões, tidos como ícones de representação regional, confirmarem a difusa, universal influência recebida, pois evidentemente seu gosto musical tinha sido formado através do rádio e do toca-discos - não faltam aí Elis Regina, Rita Pavone ou Os Beatles. O próprio Paulo Simões informa a multiface dessa "placenta musical":

"Costumava ouvir Noel Rosa, Pixinguinha, Emilinha e Marlene nos discos de 78 rotações de meus pais. Histórica e socialmente falando, a música paraguaia, unindo-se com a sertaneja, a paulista, a mineira e a gaúcha, que chegou até nós, através da Guerra do Paraguai, construiu nossa placenta musical” (Simões apud Ziliani, 2000, p. 67-68).

Daí a pertinente observação de Simões, mais uma vez:

"É difícil conviver-se com esse conceito de regional, porque se trata de mais um rótulo eficaz e eficiente para quem precisa escrever sobre o assunto. (...) me sinto aflito, quando me colocam esse rótulo. (...). Então, o rótulo funciona mais, para quem queira explicar, do que para quem faz" (Simões apud Ziliani, 2000, p. 75).

Diante do exposto, um leitor mais atento às interfaces da relação identidade versus representação não deixaria de questionar sobre o que querem significar e qual a propriedade de certos argumentos baseados, na maioria das vezes, em estereótipos do que seja realidade, literatura regionalista etc. Chegar ao ponto de cobrar-se dos escritores que escrevam ou simplesmente tematizem sobre a questão indígena - por exemplo, com o fito de justificar compromissos com a realidade, e esperar que as narrativas, inclusive a da historiografia (História da literatura sul-mato-grossense) registrem um 
agenciamento da linguagem refletidora de um topos específico (a incontestável presença das tribos indígenas na região) e em tal nome condenar a produção literária, que não estaria, por assim dizer, comprometida com as questões da realidade - resulta numa equivocada intervenção sobre a própria constituição do literário e dos protocolos de leitura de cada um dos gêneros de escrita, quando não da própria literatura como sistema modelizante, cujo texto estabelece comunicação literária específica ${ }^{7}$. Naturalmente que tais equívocos decorrem do fato de o estudioso confundir o espaço, o locus da cultura como transparência de uma representação, as condições da mimesis, e, assim intervindo na leitura das obras, não decodifica o nível de compromisso, em última análise, a vigorosa tematização do regional, do local, em obras de forte poeticidade. Seria preciso aludir à inequívoca presença daquele elemento regional na obra do escritor Manoel de Barros?

"Na ficção de Mato Grosso do Sul ou mais propriamente nos livros escritos por autores radicados neste estado, o que mais se constata é o descompromisso do autor com os contextos sociocultural, político, filosófico e até lingüístico, ou seja, há um descompromisso do autor com o seu tempo, com a sua gente. (...). Fica no ar a interrogação: por que os sul-mato-grossenses se negam a contribuir para a instauração de uma ficção de cunho regional?" (Nogueira apud Ziliani, 2000, p. 74).

Ao se abordar uma literatura, uma obra, em termos de tendência regionalista, como conceituar essa tendência quando deparamos com a produção poética de Manoel de Barros e ainda com obras como Inocência, Retirada da Laguna, Selva trágica, Estas estórias? ${ }^{8}$. Justificariam essas obras, por si sós, uma tendência regionalista, um regionalismo ligado preponderantemente ao retrato da terra, à cor local? A afirmação de que Manoel de Barros é um "legítimo representante da literatura sul-mato-grossense", exarada neste contexto e no trabalho em referência, é sustentável perante a crítica literária? E, ainda, afirmar que há uma lacuna na produção ficcional do estado, "um descompromisso dos autores com o seu tempo e com a gente" (ibidem) não traduz um desconhecimento do fato de os autores mencionados terem escrito suas obras a partir da terra e da gente sul-matogrossense? E ainda, por fim, poderiam tais obras ser indexadas, grosso modo, como sendo de tendência regionalista?

Essas indagações, todas provenientes da leitura do trabalho de José Carlos Ziliani, graças à ampla bibliografia e à diversidade de fontes aí exploradas, surgiram, como se observa, a propósito do liame na escolha do nome do 
estado de MS e as conseqüentes discussões acerca de um gentílico que possa, por força da impregnação de uma substância do conteúdo, refletir a complexidade de uma cultura, de uma região, sobre as quais ainda deve se deter uma análise condizente com a especificidade do signo narrativo.

O cidadão sul-mato-grossense diz-se incomodado quando alguém se refere ao seu estado como sendo Mato Grosso e não Mato Grosso do Sul. Alegar que os brasileiros confundem o Nome do estado não justificaria, por si só, a troca de um Nome por outro; além de revelar a ignorância dos brasileiros quanto ao espaço geográfico do próprio MT. Para nós interessa olhar com perspicácia as diversas formas de se representar uma região, deslindando o emaranhado novelo dessas formas que nos mostra, isto sim, o caráter multifacetado da realidade cultural, que se pode representar em filmes como Os Matadores, de Beto Brant, ou também pela fala de um popular anônimo, que, como nos informa Ziliani, pôs em discussão - ao mesmo tempo em que as reflete - as diferentes e diversas formas de se fazer representar. Esse popular anônimo, na cidade sul-mato-grossense de Três Lagoas, olha para a ponte sobre o Rio Paraná e lamenta: "Pena que o Rio Paraná é tão largo! Porque, meu amigo, se o Rio Paraná fosse um corguinho, Três Lagoas já tinha se separado há muito tempo de Mato Grosso" (Ziliani, 2000, p. 120).

Borrando e alargando os espaços fronteiriços, o constructo identitário obriga a revisão de antigas questões de identidade e representação culturais, dentro de uma nova região de riquezas culturais, ecológicas, turísticas e econômicas. A fisionomia cultural, ao tempo da divisão do estado, buscando sua identidade cultural, se transforma, impondo a "ruptura dos valores preestabelecidos":

"O fluxo migratório provoca a presença de outras culturas e acentua a necessidade de definir-se nova identidade, visto que os elementos que se integram à cultura sul-mato-grossense determinam o surgimento de novo processo cultural no estado" (Sá Rosa, 1990, p. 21).

Numa região fortemente vincada por todas as flexões do sintagma "migratório", o próprio entendimento do que seja uma região precisa ser revisitado ${ }^{9}$. Impõe-se sobretudo compreendê-la como dinâmica de um processo, onde a relação entre região, espaço e as representações, subsumidas "no texto e nas demais manifestações culturais", reflitam, naturalmente, sobre o processo de inscrição das diversificadas formas de representação. Com isso, o próprio componente da memória de migrantes deveria inscrever- 
se nesse amplo painel cultural ${ }^{10}$. Como bem demonstrou a estudiosa das relações entre memória e região:

“(...) uma região não é, na sua origem, uma realidade natural, mas uma divisão do mundo social estabelecida por um ato de vontade, que demonstra, na práxis, uma das premissas básicas do comparativismo, que afirma a arbitrariedade dos limites e a importância de reconhecimento das zonas intervalares, das fronteiras e das passagens e ultrapassagens. (...) A região deixa de ser um espaço natural, com fronteiras naturais, pois é, antes de tudo, um espaço construído por decisão arbitrária, política, social, econômica, ou de outra ordem qualquer que não necessariamente,cultural e literária” (Boniatti, 2000, p. 85-86).

A estereotipagem da "realidade" vem ganhando "investimentos" altamente rentáveis e procura, subliminarmente, influir na economia do texto identitário, que é, assim, denunciador da sua própria crise, ao mesmo tempo em que se instaura o problema sobre o questionamento da identidade. A estranheza do observador corresponde à do turista ou do cidadão sul-matogrossense ao desembarcar no aeroporto da Cidade Morena. A partir daí, os subprodutos da fauna pantaneira são o visível simulacro de uma realidade degradada ao nível da pura aparência das esculturas dos tuiuiús e das araras, tucanos e aves, todos pintados com requintes naturalistas, com hiperestilização da aparência calcada em matriz ecológica, que embebesse o olhar do habitante da cidade e que dispensaria, mediante este cenário desenhado/pintado e atirado ao olhar do espectador, a razão e necessidade de se visitar e conhecer o Museu Dom Bosco - o espaço próprio para a exposição de todo o bicharéu empalhado.

Com base num discurso ecológico, politicamente correto, agencia-se uma "topografia do imaginário", o imaginário paradisíaco (terra e mundo edênicos) construído com fortes cores e tintas, argamassa e cimento que pouco ou nada tem de "santuário ecológico do mundo" status de arte "sacralizada", que nas mãos do artista/artesão se converte na "bicharada no cimento", plasmando de vez o kitsch da cultura do consumo.

Matéria do jornal O Progresso, de 24/09/01, divulgou propositura de vereador que quer melhorar o sistema de orientação da cidade, promovendo a "reprodução, em obras de arte, de aves e animais típicos da região, para servirem como ponto de referência, além de proporcionar o embelezamento da cidade." Pode-se até argumentar em favor da colocação de animais típicos da região, como garças, jacarés, tuiuiús, emas, seriemas, onças e 
capivaras, nos cruzamentos da cidade, em nome de uma cultura do kitsch, pois grande parte dos espectadores, admiradores dessas obras, não se elevou ao nível de poder, se não avaliar e julgar, ao menos reconhecer o que seja um objeto artístico. Mas, era de se desejar que essa topografia imaginária pudesse transformar-se nos "trópicos imaginários" de que fala a escritora Raquel Naveira, desmanchando todo equívoco autorizado. E no lugar de esculturas de araras e bichos abrigando cabinas de telefone, o espectador/ leitor consciente possa perceber que uma das condições da obra de arte é o seu não-embelezamento e o não-empalhamento da natureza.

Mais recentemente, compondo o perfil de uma literatura regional, o poeta-performer, douradense, Emmanuel Marinho, vem realizando significativa produção artística que privilegia expressões da realidade e do cotidiano da região. Num dos textos de Emmanuel, mais amplamente conhecido e explorado, "Genocíndio", propõe-se uma vigorosa denúncia da condição de expropriação e espoliação a que tem sido submetido o índio e sua cultura em toda a região sul do estado - "Genocíndio", poema-apólogo do quase extermínio da população indígena local.

Também o poema "Índia velha", outro símbolo do clamor indígena, torna patente a metáfora do "corpo despedaçado", na medida em que a representação do regional se constrói sobre os signos do arcaico e do moderno: de um lado, o universo indígena, sofredor do processo de aculturação; de outro, o mundo urbano criado pelo homem branco (Perentel, 1999, p. 20).

Apesar de ser lembrado, regionalmente, como o autor dos versos de "Genocíndio", o poeta Emmanuel Marinho mereceria antes ser celebrado como o autor de "Margem de papel" e pelo mais recente trabalho publicado, o disco "Teré", em que ele próprio lê e interpreta alguns de seus poemas uns já conhecidos, outros novos e originais. No caso desse disco, merece destaque especial o redirecionamento que o autor passa a imprimir não só ao processo de reelaboração de sua temática regional, mas sobremodo pelo surgimento de um registro que de modo objetivo se torna a formulação e a constituição de uma matriz poética resistente ao rótulo de literatura regional, tout court.

Neste nível, o poema "Genocíndio" compõe-se de outro texto cujos sentidos se entranham na análise do próprio poema: "a poesia é suja de som? De sonhos / de sangue de signos. / (...) a poesia lê o mundo / inventa outros / mofa nas gavetas / arranha paredes / perturba a ordem pública / e protesta nas praças pela paz". A partir daí, pode-se avaliar nitidamente a evolução da obra de Emmanuel, que, vindo de um sistema regional inicialmente arti- 
culado com uma realidade político-literária, encaminha-se para o polissistema nacional, não anulando a tensão entre o regional e o nacional (Cosson, 1998, p. 86).

Conforme se percebe nesses outros versos, pelos quais o poeta é nacionalmente conhecido: "poesia não compra sapato mas como andar sem poesia?”. Entretanto, tal evolução que aqui se constata não pressupõe, ainda, um distanciamento do poeta a uma temática própria da literatura regional, uma vez que o conjunto de sua obra, e o próprio título "Margem de papel", se deixa indexar ostensivamente sob os restos, as margens e as multifaces do conturbado solo que constitui a representação cultural: ou seja, o corpo despedaçado do texto, na sua matriz representativa, atua sobre o emaranhamento da problemática identidade versus representação, e o texto acaba atuando, ainda, como margem de papel, e da folha, indicando o macrotexto sócio-político-cultural que compõe a região - o entorno do pantanal mato-grossense.

Aliás, o próprio processo de reduplicação de um único tema, o genocíndio, evidencia deslocamentos agenciadores de possibilidades plásticas, na medida em que os dois textos escritos sob um mesmo título (Genocíndio) desdobram o eixo temporal em sua simultaneidade de passado e presente. Com isso, não só o espaço e o tempo se recuperam em seu nomadismo, volatilidade plástica, mas sobredeterminam o próprio universo do discurso, ou da representação. Quer dizer, a partir do paratexto-título "genocíndio", Emmanuel Marinho escreve dois poemas comprovadamente diferentes, quer seja no que se refere ao espaço que cada um ocupa na ordenação e paginação das respectivas obras, na série-conjunto das obras do autor, quer seja com relação ao objeto e signos aí representados.

No entanto, a análise comparativa dos dois textos é extremamente produtiva na atualização dos sentidos que se encontram e se cruzam, compartilhando seus respectivos espaços de significação. Da perspectiva do poetaartista-ator, o refrão "tem pão velho?" (ato performático de crianças indígenas batendo palmas nos portões), que se repete ao longo das seis partes do poema, dramatizando a dilaceração do elemento indígena, finda, no segundo texto e segunda versão de "Genocíndio", absorvido plenamente pela matriz poética, lírica, do poema que, agora, encerra em si o espaço e o tempo da sua representação, no qual a temática da realidade, o elemento indígena potencializado já pelo paratexto-título, permite-se ler na própria materialidade do ser poético, uma vez que "a poesia é suja de sangue e de signos".

Somente acompanhando os retalhos que compõem a obra no seu todo é 
que se pode apreender as interrogações que o texto de Emmanuel faz eclodir: eclodir, por exemplo, a questão da identidade, do autor, do leitor, de um mundo em perplexidade. Desse significante brota a certidão, o registro de nascimento, que abre a própria obra: na folha, despedaçada, está a certidão de nascimento. Seria a certidão do poeta? Registro e/ou certidão recortados, como a escrita esfacelada e fragmentada da "cartilha" e de outros textos que também compõem a obra; todos retalhos de um fio de navalha que vai cortando cada página até a des/configuração plena das folhas em branco, sem escrita, assumindo de vez a descoloração da escrita para ganhar, no final, o colorido do arco-íris. Não transigindo com uma gramática, a obra é margem de papel, margem de palavras, que resgatará a identidade extraviada dos seres e das coisas - "papel sem margem como eu", como diz o poeta.

Ao lado de uma denúncia pelas margens e entrelinhas do próprio texto, corre também uma citação constante, o retalho de outros textos com os quais Emmanuel trava um diálogo poético-performático: Manoel de Barros, Borges, Dali e Mallarmé. Nesse gesto de apropriação, Emmanuel brinca com o papel, jogando com as estereotipias do estabelecido como se quisesse gritar, com suas palavras, que nada existe, que é para além da margem da identidade oficial e aparente que se deve olhar. Ou, não seriam as coisas feitas apenas de papel, não seríamos nós todos apenas seres de papel?

A questão da identidade cultural, hoje, parece estar vicariamente ligada ao que Stuart Hall caracteriza como algo que flutua livremente, decorrente de uma sociedade regida por imagens da mídia e pelos sistemas de comunicação globalmente interligados (Hall, 2001, p. 71-75). Para esse sistema de identidade cultural, o sujeito é o que se vê espelhado nos fragmentos e nas fraturas e sua identidade resultaria num plano de "geografias imaginárias". Não seria mais apropriado, então, localizar a questão de nossa identidade cultural para além dos estereótipos que pré-moldaram a questão da identidade e da representação? Adotando, assim, a perspectiva da escritora sulmato-grossense, Raquel Naveira, que no poema "Limites" explora os "trópicos imaginários", questionando o frágil, a fronteira, o extremo, que des/ limitam essas geografias? Algo, "que escapa de meus dedos / Como um pássaro sem pluma". Não estaria entranhada nesses versos, na vigorosa metáfora do movimento que eles engendram, a possibilidade de refletir acerca da construção identitária de MS?

Concluindo esta exposição, evoco uma passagem de Homi Bhabha, em sua obra DissemiNação, para, com essa passagem, lembrar aqui a neces- 
sidade atual de reinvenção e recriação das diferentes identidades culturais.

“As pessoas não são simplesmente eventos históricos ou componentes de um corpo político patriótico. São também uma complexa estratégia retórica de referência social em que a alegação de ser representativo provoca uma crise dentro do processo de significação e endereço discursivo" (Bhabha, 1995, p. 16).

Parece que a crise e o impasse tendem a permanecer enquanto a nossa reflexão não se conscientizar de que estaremos, repetidamente, fazendo a mesma pergunta que, a meu ver, já está inscrita na lápide - citação em exergo - de um corpo fantasmático que nos obrigará, sempre, a voltar à sepultura. Talvez para nos lembrar que a complexa relação entre identidade e representação deverá ser procurada, hoje, no ato de des/limitar as fronteiras de ontem, rumo aos espaços intervalares que se reconstituirão, assim, reinventando o presente e o futuro.

Em uma crônica, escrita em julho de 1934, o escritor Rubem Braga, em rápidas porém fortes pinceladas, já anunciava o perfil de um estado: "Mato Grosso é um palco à procura de personagens"; registrando, à época, que "a bela Campo Grande toda orgulhosa e rica que, de tão rica e orgulhosa, já anda querendo se separar de Mato Grosso, dizendo que o Norte do Estado explora o Sul, que o Sul deve deixar de ser Mato Grosso para ser Maracaju etc." (Braga, 1982, p. 44-46). Leiamos a abertura desta crônica intitulada "Mato Grosso", caracterizando um traço fundamental para a verificação da constituição identitária do Estado de Mato Grosso do Sul: "Três Lagoas, será Mato Grosso? Saltamos do trem e a poeira de nossas roupas é poeira paulista; e este cigarro que fumo foi aceso em São Paulo. Conversei com três cidadãos de Três Lagoas, e eram três paulistas."

\section{Referências Bibliográficas}

ANGENOT, M.; BESSIÉRE, J.; FOKKEMA, D.; KUSHNER, E. Teoria literária: problemas e perspectivas. Lisboa: Publicações Dom Quixote, 1995. p. 223-349.

BESSIÉRE, J. Literatura e representação. In: ANGENOT, M. et al. Teoria literária: problemas e perspectivas. Lisboa: Publicações Dom Quixote, 1995. p. 377-394. 
BHABHA, H. K. DissemiNação: tempo, narrativa e as margens da nação moderna. Belo Horizonte: UFMG, 1995.

BIASOTTO, W. V. Prá quem fica a seriema?. Jornal O Progresso, Dourados, 10 mai. 1999.

BONIATTI, I. M. B. Literatura comparada: memória e região. Caxias do Sul: EDUCS, 2000.

BRAGA, R. Mato Grosso. In: ___ O conde e o passarinho. Rio de Janeiro: Record, 1982.

COSSON, R. "Notas à margem de uma fronteira móvel". In: CONTINENTE Sul/Sur, Porto Alegre: Instituto Nacional do Livro, 1998. v. 7, p. 85-94. COUTO, C. M. O Guizzo é que tinha razão. Jornal O Progresso, Dourados, 11 jun. 1999.

FERNANDES, J. G. Um paraíso imaginário ou a bicharada no cimento. Revista de Letras Papéis, Campo Grande, v. 1, n. 1, 1997.

GUIZZO, J. O. História e estórias de uma velha pendenga revisitada. Revista MS Cultura, Mato Grosso do Sul, n. 3, set./out. 1985.

HALL, S. A identidade cultural na pós-modernidade. Rio de Janeiro: DP\&A Editora, 2001.

MARINHO, E. Margem de papel. Dourados: Manuscrito Edições, 1994. MARINHO, E. Teré. Manaus: Compact disc, 2002. 1 CD (80min): digital, stéreo.

MINER, E. Estudos Comparados Interculturais. In: ANGENOT, M et al. Teoria literária: problemas e perspectivas. Publicações Dom Quixote, 1995. p.199-221.

NAVEIRA, R. Casa de tecla. São Paulo: Escrituras Editora, 1998.

NOLASCO-SANTOS, P. S. Um outdoor invisível: imagens do pantanal sulmato-grossense. In: CARVALHAL, T.F. (Org.). Culturas, contextos e discursos: limiares críticos no comparativismo. Porto Alegre: Editora da Universidade, 1999, p. 175-183.

NOLASCO-SANTOS, P. S. Obre Emmanuel Marinho. Jornal O Progresso. Dourados, 29 nov. 1994.

PERENTEL, E. de R. O lirismo e a dramaticidade de Emmanuel Marinho. 1999. Monografia(Especialização em Literatura Comparada).-Universidade Federal de Mato Grosso do Sul. Dourados.

SÁ ROSA, M. G. Deus quer o homem sonha a cidade nasce: Campo Grande, cem anos de história. Campo Grande: FUNCESP, 1999.

SÁ ROSA, M. G. Memória da cultura e da educação em Mato Grosso do Sul. Campo Grande: UFMS, 1990. 
SENA, C. Fronteira Centro-Oeste. Brasília: Kelps, 1999.

SILVA, V. Estado do PT e a seriema. Jornal O Progresso. 10 mai. 1999. ZILIANI, J. C. Tentativas de construções identitárias em Mato Grosso do Sul (1977-2000). Dissertação (Mestrado em História do Brasil)-Universidade Federal de Mato Grosso do Sul, Campus de Dourados. 2000.

\section{NOTAS}

1 Este trabalho, reformulado, foi originariamente apresentado no I Colóquio Sul de Literatura Comparada e Encontro do GT de Literatura Comparada da ANPOLL - Trans/versões Comparatistas, na UFRGS/Porto Alegre, de 8 a 10/10/01. Integra também o projeto de pesquisa Nomes e Faces: a literatura comparada no extremo oeste do Brasil, em desenvolvimento na linha de pesquisa Literatura e estudos regionais, culturais e interculturais

2 Doutor em Literatura Comparada pela Universidade Federal de Minas Gerais, professor adjunto da Universidade Federal de Mato Grosso do Sul; coordenador do GT de Literatura Comparada da ANPOLL, coordenador do Curso de Letras do CPDO/UFMS.

3 Cf. artigo As condições econômicas e a divisão, de autoria do professor Gilberto Luiz Alves, REVISTA MS Cultura. n. 3, set./ out. 1985.

4 Cf. nosso artigo Um outdoor invisível: imagens do pantanal sul-mato-grossense, In: CARVALHAL, T. F. Culturas, contextos e discursos.

5 Cf. O Guizo é que tinha razão, de Carlo Magno Couto, O Progresso, de 11/06/99.

6 Além dessas duas crônicas, outras também demonstram a atenção dada ao assunto: Estados de Mato Grosso do Sul e do Norte, de Primo Fioravante Vicente. O Progresso, 29/04/99.; Mato Grosso do Sul ou Pantanal?, de Adauto de Oliveira Souza. O Progresso, 08/05/00; Muda MS, muda!, de Willams Araújo. O Progresso, 01/05/99; Aplicações práticas da ideologia das luzes, de José Beltrão de Medeiros. O Progresso, 09/05/99.

7 Sobre a questão, cf. Teoria Literária - problemas e perspectivas (ver referências bibliográficas).

8 As obras literárias em referência foram citadas por Ziliani, em sua dissertação, como sendo representantes da literatura regional.

9 Neste sentido, cf. o excelente ensaio Estudos Comparados Interculturais (MINER, 1995).

10 SÁ ROSA (1999. p. 36). A professora Glorinha publicou importantes obras sobre depoimentos, memórias e histórias de vida da gente mato-grossense. Cf. também SENA (1999).

$11 \mathrm{O}$ professor José Genésio Fernandes realizou importante leitura semiológica das imagens de bichos pintadas nas paredes dos prédios da cidade de Campo Grande. Cf. "Um paraíso imaginário ou a bicharada no cimento". 
On the Margins of the Paper, or the Text's Shattered Body

This article reflects on the passage of signs through the socioeconomic universe of the State of Mato Grosso do Sul, Brazil, and the establishment of identity and representation in various texts from both the literature and cultural critique dealing with the issue. Adopting a perspective based on cultural critique and/or cultural studies, the article analyzes the complexity of the relationship between narration and representation, elaborating a synthesis of the notion of region in the area around what is known as the Pantanal (Swampland) in Mato Grosso do Sul. The study concludes that the passage and circulation of cultural signs occur as a discursive agency which alternately reflects both the object of representation and the mask, since the nature of this object appears as the emblematic fabric of a shattered body.

Keywords: Identity and representation; cultural studies; critique.

Recebido em: 20/09/2002.

Aprovado em: 12/11/2002. 